This is a postprint (final submitted manuscript) version of the following article:

Parris, D. (2013). Conceptually meeting expectations of Generation Y by building personalised-customised hybrid bundles to target action sports consumers. International Journal of Revenue Management, 7(2), 138-154. https://doi.org/10.1504/IJRM.2013.055685 


\title{
Conceptually Meeting Expectations of Generation Y by Building Personalized-Customized Hybrid Bundles to Target Action Sports Consumers
}

Running Title: Personalized-customized hybrid bundling

\begin{abstract}
This paper conceptually explores how bundling could lead to greater revenue and brand loyalty in the action sports industry by meeting the expectations of Generation Y. The author defines personalized-customized hybrid bundles and proposes using these bundles to target Generation Y action sports consumers. Generation Y grew up in an even more mediasaturated and brand-conscious world then their parents. They use brands for self-expression to define what is 'cool' and seek counter cultures such as action sports. They expect a virtual dialogue with companies and comparison shop quickly. The author explores how bricks-andclicks retailers can sell distinct products with different costs in a bundle through utilizing multichannel customer management (MCM) in combination with customer's self-selection. A conceptual model is developed explaining how action sports capture Generation Y, and a second model demonstrates how MCM combined with customer self-selection can be used to create personalized-customized hybrid bundles.
\end{abstract}

Keywords: branding, coolness, action sports, Generation $Y$, lifestyle marketing, personalization, customization, bundling, self-selection, multi-channel customer management, personalizedcustomized hybrid bundles, differential pricing

Conceptually Meeting Expectations of Generation Y by Building Personalized-Customized Hybrid Bundles to Target Action Sports Consumers 


\section{Introduction}

The 20 years gap between Generation X (born between 1965 and 1978) and Generation Y (born between 1979 and 1994) witnessed the disruptive innovation of the Internet, which created divergent consumer markets. Generation $\mathrm{X}$ witnessed the introduction of the home computer (in 1976 Apple I computer was released) and video games (in 1980 Pac-Man was released), played traditional sports, shopped at bricks-and-mortar stores, and survived most if not all of college without Google or a personal laptop. In contrast, members of Generation Y do not remember a life without mobile devices, e-commerce, online gaming, social media, and action sports. The Internet is the media of choice for Generation $\mathrm{Y}$ while Generation $\mathrm{X}$ grew up with MTV. The Internet sped up the fashion life cycle for Generation Y; whereas, television drove homogeneity for Generation X (Business Week, 1999). Demand for diversity and a 'cool' factor catalyzed a fundamental shift in the sport industry.

Generation Y sought sports that offered different ideological or practical alternative activities from the values of mainstream sports (Rinehart, 2000). The desire for individualism, risk, lack of conventional rules, freedom of self-expression, and the ability to break established limits of Generation Y sparked the extraordinary growth of action sports. Representing almost $25 \%$ of the population in the United States, out numbering the Baby Boomer Generation (born between 1946-1964) by 4 million, and replacing them as the most important economic force makes Generation Y a highly coveted consumer market (Escalera, 2012). Despite these facts, there is very limited research on best business practices, pricing strategies, consumers' behavior, and effective marketing strategies for the action sports industry. The challenge for marketers interested in attracting Generation $\mathrm{Y}$ is how to reach and subsequently maintain them as consumers. 
Generation Y consumers' expect interactions with companies and comparison shop quickly while accessing social media. They are disloyal, and difficult to secure as repeat customers (Lazarevic, 2012). Online media has set the expectation of a virtual two-way dialogue where brands and companies provide immediate responses. A space where consumers anticipate that if they act, then the retailer will (re)act in a manner that is accurate and on a personal level with their desires (Adamson, 2008). Bricks-and-mortar stores can complement their store offerings with online channels allowing for improved operational efficiencies, and increased benefits to customers (Zhang et al., 2010). The interactive role between bricks-and-clicks retailers (retailers that have bricks-and-mortar stores in conjunction with an Internet store) and customers has made online interactions feel as comfortable and familiar to consumers as offline interactions (Adamson, 2008; Zettelmeyer, 2000). Higher consumer expectations for personalized and customized online interactions has lead to the innovation of multichannel customer management (MCM) systems:"the design, deployment, and evaluation of channels to enhance customer value through effective customer acquisition, retention, and development" (Nelsin and Shankar, 2009, p. 70). MCM systems allow companies to offer increased personalization and customization to their customers (Adamson, 2008; Neslin and Shankar, 2009; Pan et al., 2002). Giving Generation Y consumers the individual interaction they expect requires personalization combined with customization.

The action sports industry needs to address how to sustain and advance a relationship with their target market, Generation Y. The information collected from MCM and technological advances have enabled bricks-and-clicks retailers the ability to create a win-win situation for the company and customer by offering personalized-customized hybrid bundles. The author defines a personalized-customized hybrid bundle as a single firm's offering of two or more distinct 
products at different prices in a bundle created by the MCM system based on the customer's preferences in conjunction with the consumer's self-selection. One-on-one marketing creates a virtual dialogue by employing personalization and customization. As the consumers shop online the retailer can analyze what they are searching for, the specific features of the products that interest them, what they are experiencing, what they are doing relative to the buying process, and what offers they deem relevant (Adamson, 2008; Neslin and Shankar 2009). This interactive communication provides access to consumers' preferences, which enables the firm to personalize product bundles from different menus of product attributes to different customers (Arora et al., 2008; Huffman and Kahn 1998; Liechty et al., 2001). The next step in building a relationship with customers is allowing them to become stakeholders throughout the buying process by offering self-selection via customization (Hitt and Chen, 2005). Subsequently, additional value to the customers can be provided by offering hybrid product bundling that integrates the sale of two or more distinct products at any price.

The aim of this paper is to conceptually explore personalized-customized hybrid bundles in the action sports industry. By exploring how bricks-and-clicks retailers can sell distinct products with different costs in a bundle using MCM systems combined with customer selfselection. Action sports companies - the 'cool' counter culture sports, can use bundling to build brand loyalty with Generation Y action sport consumers. A conceptual model is developed to explain how action sports capture Generation Y, and a second model demonstrates how MCM in conjunction with customer self-selection can be used to create personalized-customized hybrid bundles. Personalized-customized hybrid bundles allow Generation Y consumers the freedom, control, and the fun of constructing their own bundles to fit their own individual wants and needs. 


\section{The Market: Generation Y and Action Sports}

\subsection{Generation Y's self-branding}

Global media communicates and defines 'cool' consumption activities for Generation Y (Ferguson, 2011; Goodman and Dretzin, 2001). The macro-environment influences media, peers, and family to form distinct social-cultural generational cohorts (Schewe and Noble, 2000). The Generation Y cohort grew up in a brand saturated environment and consequently responds differently to brands (Lazarevic, 2012). A brand attaches symbolic meanings to a company’s products by creating an image, building a reputation, defining values, and expressing a 'lived' experience to differentiate from other brands. Unlike other generations, Generation Y utilizes brands as an extension of themselves (Novak et al., 2006). The brand image of the product must be congruent with Generation Y's image of themselves for them to judge the brand as appealing, which is a fundamental antecedent of loyalty (Keller, 1993; Morgan and Hunt, 1994). Brands must meet Generation Y's need for self-expression and satisfy an image they want to be associated with their identity (Rajamma et al., 2010; Saxton, 2007). Bricks-and-clicks retailers and marketers need to offer products that fit the consumer characteristics of Generation Y's selfbranding image.

\subsection{Generation Y consumer characteristics}

Generation Y shoppers (also known as the millennials) represent the largest generation and consumer group in U.S. history and will ellipse Baby Boomers spending power by 2017. Their purchasing power exceeds $\$ 200$ billion dollars in addition to influencing over half of all economic spending in the U.S. (Archer, 2012). Marketing to Generation Y requires a different approach compared to their parents who represent the Baby Boomers or Generation X (Herbig et al., 1993). The most important difference between the generations is the explosion of the 
Internet. The proliferation of media choices which has resulted in: sophisticated media literacy, greater product diversity, increased lifestyle choices, amplified expectations of choice as well as control, and a strong materialistic image of what is 'cool' for Generation Y (Ferguson, 2011). Unlike their parents, Generation Y grew up where shopping was no longer a simple exchange. The explosion of product choices and the ability to shop online as well as on mobile devices has made shopping an interactive form of entertainment, sport, and social encounter (Aqunio, 2012; Bakewell and Mitchell, 2003). As teens Generation Y grew up being socialized by TV (an average of 7 hours per day) creating a consumption obsessed culture where "material things and opulence are good and desirable" (Bakewell and Mitchell, 2003, p. 98). Compounded by having more disposal income than any other group in history, Generation $\mathrm{Y}$ is considered the freestspending generation in addition to the hardest to reach (Hyllegard et al., 2011; Noble et al., 2009). Consequently, their consumption behaviors and expectations are distinct compared to their predecessors.

The norm for Generation $\mathrm{Y}$ is interacting and communicating extensively through social media in combination with their mobile device continuously throughout the day. Social media includes: collaborative projects (e.g., Wikipedia); content communities (e.g., YouTube); virtual game worlds (e.g., World of Warcraft); virtual social worlds (e.g., Second Life); and blogs (Kaplan and Haenlein, 2010). Generation Y is well educated and technology dependent (Nobel et al., 2009). They have grown up with high expectations of companies to be accessible 24 hours a day 7 days a week, and where digital marketing channels deliver more for less, routinely for free. As savvy patrons they are not particularly receptive to traditional marketing methods, skeptical of advertising, difficult to obtain as consumers, and even harder to retain as loyal customers (Lazarevic, 2012; Syrett and Lammiman, 2004). Although dubious of traditional 
marketing, Generation Y are peer dependent (tribal in nature) and do their research seeking out valued opinions from their peers, family, and their social media community to make product choices (Nusair et al., 2011; Stone et al., 2001). Individually Generation Y consumers seek to be respected by their peers; therefore, they ensure their purchases represent a 'cool' self-brand (Goodman and Dretzin, 2001). The desire is for Generation Y's self-brands to reflect the values of peers (tribe) and enable them to express their own unique identities. Consumption provides a free space to find oneself by helping Generation Y define "who they are, what is important to them and what they value in life" (Nobel et al., 2009, p. 626). According to Fernandez (2009), Generation Y consumers want the image of success, wealth, class, style, and being better. Generation Y seeks the "cool” factor through consumption.

\subsection{The 'cool' factor}

The 'cool' factor for Generation Y is defined by the brands they wear, music they listen too, activities they pursue, and the meaning connected to their materialistic consumption (Goodman and Dretzin, 2001). Coolness is part of any culture that values individual differences. The appeal of coolness is engendered by an individual's or a cohort's pursuit of being labeled (i.e., branded) as 'cool' because it is a socially significant rite of passage. A cool brand denotes social inclusion (belonging in 'the' tribe); whereas, not being 'cool' implies exclusion (an outsider). Conceptually coolness is defined by two distinct orientations: "one outward focused attuned to external valuations, the other more independent, rebellious and countercultural" (Dar-Nimrod et al., 2012, p. 175). Cool is often associated in opposition to mainstream culture and represents a rejection of standardization and conformity (Ferguson, 2011). Generation Y's desire to be ideologically distinct from their parents - to be 'cool', catalyzed the growth of action sports. 


\subsection{Action Sports}

The convergence of action sports entering the Olympics and the corporate desire to reach the very elusive Generation Y have provided a prime opportunity and challenge for marketers (Gladden, 2006). Action sports (i.e., wakeboarding, motocross, BMX freestyle, surfing, windsurfing, skateboarding, snowboarding, and freestyle skiing) are predicted to outpace the sales of more traditional sports (Beal and Wilson, 2004) such as traditional team sportsfootball, basketball, baseball, and hockey, and individual mainstream sports - tennis and golf. 2010 marked the fourth year snowboarding was in the Olympics; NBC's telecast during the snowboarding finals drew 30.1 million viewers, 11.7 million more than American Idol, the first time any broadcast beat American Idol in six years (Today, 2010). The premier action sports event is the Winter X Games, which in 2012 had: 108,000 on-site attendees and 35.4 million TV viewers in the U.S., a $32 \%$ increase from 2011, with a $16 \%$ increase in the core target demographic, Generation Y. Vital to the X Games success was aggressive mobile and social media marketing: X Games mobile phone app 2.5 million page views and 1.8 million total minutes; Facebook 2.5 million fans; YouTube 8.5 million views during the two week window of the event; and Twitter 150,000 fans (Hargrove, 2012). Generation Y is fascinated with the individuality, risk, and danger of action sports (Koranteng, 2002). As a counterculture, action sports are the image of 'cool' by encouraging innovation, freedom, rebellion, self-expression, and breaking of established norms.

The counterculture of action sports is reflected in the birth of the industry. Action sport companies' originally started as end-user entrepreneurial start-ups. Founders of action sports were hobbyists and sport enthusiasts who developed the sport by creating innovative solutions to the limits of already established sports (Shah, 2004). For example, windsurfing was adapted from 
sailing, and snowboarding was adapted from snow skiing. As participation in action sports increased the companies transitioned from end-user entrepreneurial start-ups to medium-large scale businesses that manufacture base products. The base product producers (i.e., snowboarding - Burton, wakeboarding - Hyperlite, windsurfing - Neilpryde) sell their products to end-users, bricks-and-mortar small independently owned 'local' shops, and bricks-and-clicks local, regional, or global retailers (Desborders, 2002). Similar to the technology industry, action sports companies were founded by individuals driven by motives such as enjoyment, challenge, and a desire to build a product that would allow them to achieve what previously was unachievable. These companies were driven by product innovation designed by the end-users. To date, the marketing of action sports companies is mainly focused on product innovation even though only a few elite athletes understand the minute technological advances.

Action sports companies find themselves in the same position as Nike did in the mid1980s. Nike originally believed that product innovation was the driving factor to success; however, Nike realized product innovation was not sufficient to maintain its market share and obtain future growth. Nike redefined itself as a marketing company with the product as the most important marketing tool (Willigan, 1992). Action sports companies are starting to follow Nike's example and re-evaluating their strategic emphasis from innovation to marketing. For instance, in response to the increasing demand for diversity, action sports companies are beginning to adopt multi-brand strategies. A multi-brand strategy is when a firm develops two or more products in competition under distinct brand names that target specific consumer segments (Giannoulakis and Apostolopoulou, 2011). As action sports become more mainstream companies are responding by offering diverse products that range from targeting the authentic core riders to non-riders (mainstream markets) who want to identify with the 'cool' status of these sports. 


\subsection{Lifestyle of 'cool' consumption}

Consumption of action sports is not simply about acquiring, using and disposing of one product but the consumption of a basket of products (Funk, 2003). The lifestyle of action sports consumers includes the consumption of music, apparel, sporting equipment, movies, documentaries, books, video games, events, and concerts (Wheaton, 2004). According to Hanan (1980), lifestyle marketing (LM) captures the target market by creating an association between the company's brand or cause by tailoring the marketing message to match the consumers' lifestyle, interests and opinions (psychographics), and their recurrent patterns of behavior. Action sports have developed a subculture within the sport itself. An important part of the action sports subcultures that appeals to Generation Y participants is the authenticity of the sport, which defines what is, and what is not, part of the sporting culture (Amato et al., 2005). A large part of who is an authentic core rider, and who is not, is represented by the products worn, used, and consumed.

Action sports are unique in that individual participants need a "basket of goods" to be able to participate in the sport. For example, as shown in Figure 1, to snowboard one needs: a snowboard, bindings, boots, a snowboard leash, snow pants, snow jacket, gloves, a hat, a helmet, snowboard socks, thermal underwear, multi-layer clothing to stay warm, camelback, and additional assorted gadgets such as freeze-proof IPod cases and ear phones.

Table 1 Product categories in the action sport of snowboarding

\begin{tabular}{|c|c|c|}
\hline Hardline Products & Softline Products & Accessories \\
\hline Snowboard & Hat & Ipod case (music) \\
Binding & Goggles & GoPro (camera) \\
Boots & Jacket & Camelback (hydration) \\
& Gloves & \\
& Pants & \\
\hline
\end{tabular}


Many times customers enter a bricks-and-mortar store and purchase a complete bundle of products. As quoted by Cathy Williams (personal communication, December 1, 2012) — a retired professional wakeboarder with over twenty years of experience in the retail industry of action sports at Performance Ski and Surf (a local bricks-and-clicks retailer with a physical store in Orlando, Florida), "many parents come in and say my kid wants to be like, NAMED PRO. I want my kid to have everything NAMED PRO uses and they end up purchasing a whole bundle of goods". The possibility of becoming a celebrity has been communicated to Generation Y through social media (Turner, 1999). In action sports, the innovation of the GoPro a pocket video camera that allows sport participants to record themselves has sold "over $\$ 2$ billion world-wide, growing 21\% in unit sales to 13.5 million in 2010 from the prior year" (Wingfield, 2011, p.1). Generation Y has developed a value system where success is linked with fame, and the cohort has been called 'cult of celebrity' where performance is fame in the making (Turner, 1999). As stated earlier Generation Y seeks that status of 'cool' through consumption.

In order to support 'cool' consumption individuals are choosing to purchase products as a bundle; however, the industry only sells items individually. It is important to note that due to the diversity of these products the unit costs will vary. For instance, the marginal cost of a snowboard jacket (softline product) will be very different then the marginal cost of a snowboard (hardline product). In addition, the same line of products either soft or hard will have different costs; a snowboard will have higher marginal cost than boots, and boots will have a higher marginal cost than bindings. Personalized-customized hybrid bundling integrates hardline, softline, and accessory products into a price bundle. To address the purchase behavior of Generation Y action sports consumers the author purposes a model.

\subsection{Proposed Conceptual Model for Action Sports to capture Generation Y}


First to capture Generation $\mathrm{Y}$ action sports consumers it is paramount to develop a brand that consumers identify with and wish to be associated. Next, marketers must leverage Generation Y's consumer characteristics. Third, companies need to cultivate their 'cool' factor. Fourth, action sports align with Generation Y's search for coolness. Finally, Generation Y purchases a bundle of products to self-brand through their 'cool' consumption. Given that action sport consumption represents a lifestyle that includes a basket of products, and that participation in the sports requires a basket of products, the author proposes the action sport industry and consumers would benefit from personalized-customized hybrid bundling. The concept of personalizedcustomized hybrid bundling was formulated by integrating research on personalization, customization, and bundling.

\section{Literature Review}

\subsection{Personalization and Customization}

Personalization and customization are two forms of one-on-one marketing that facilitate modification of one or more aspects of the firm's marketing mix to target a group of individual customers instead of the firms' entire consumer base (Arora et al., 2008; Peppers and Rogers, 1997; Shaffer and Zhang, 2002). Personalization is when a firm selects relevant information suitable for an individual customer based on previously collected information (Arora et al., 2008; Won, 2002). Customization occurs when a consumer proactively self-selects one or more components of the firm's product offering to design their own product bundle (Hitt and Chen, 2005; Arora et al., 2008). MCM systems enable the bricks-and-clicks retailers to personalize the offering to the consumer through analysis of past and current shopping patterns while at the same time the consumer can customize and build their own product bundles. For instance, if a female 
snowboarder was shopping online the MCM would personalize the products displayed, and the interface would allow the customer to customize a hybrid bundle of products.

Despite the potential benefits of combining the elements of personalization and customization, there is little research on the topic nor has it yet to be applied in industry. The literature is divided into analyzing personalization and customization as separate themes. Examples of bricks-and-clicks retailers that use personalized offers such as Amazon's personalized recommendations for books and music are plentiful (Arora et al., 2008). Personalization focuses on building a meaningful one-on-one relationship with each customer by understanding their needs and helping them satisfy those needs efficiently and effectively. An additional way for a bricks-and-clicks retailer to build a meaningful one-on-one relationship with customers is through customization.

Customization makes customers stakeholders in the buying process by giving them a proactive role in the product selection process. In providing customers with a proactive role in the buying process, a bricks-and-clicks retailer has the ability to fulfill the needs of experimental shoppers who are shopping for fun and goal-directed shoppers whom are shopping for efficiency by giving them a higher locus of control (Wolfinbarger and Gilly, 2001). As stated previously Generation Y view shopping as a form of entertainment. An example of a company that has uses customization as a competitive advantage is Dell, a personal computer company. Dell enables consumers to self-select one or more parts of a personal computer (PC) system to form a product bundle (Stremersh and Tellis, 2002). An advantage of combining personalization and customization is increased consumer lock-in, which decreases consumer's propensity to switch bricks-and-clicks retailers after an initial investment has been made (Zauberman, 2003). Obtaining loyalty from Generation Y shoppers has been difficult due to their ability to quickly 
comparison shop combined with their high expectations (Lazarevic, 2012). An online shopping experience could allow both personalization and customization by offering consumers the control and freedom to build their own product bundles, which would result in increased customer purchases and loyalty.

\subsection{Bundling}

Stremersch and Tellis (2002) define bundling as the sale of two or more separate products in a package, and define separate products as products, in which separate markets exist. Separate market exist when at least some buyers want to buy the product independently. There are three distinct forms of bundling; (a) pure bundling, in which a firm sells only the bundle and not (all) the products separately, (b) mixed bundling, in which a firm sells both the bundle and (all) the products separately, (c) unbundling, in which a firms sells all products separately (Lilien et al., 1992). Currently, the action sports industry has adopted an unbundled strategy. Bundles can either be based on price bundling or product bundling. Price bundling is the sale of two or more separate products in a package at a discount, without any integration of the products; whereas, product bundling is the integration and sale of two or more separate products or services at any price (Stremersch and Tellis, 2002). A combination of price bundling and product bundling based on a MCM system in conjunction with consumer interaction would allow for customized bundling.

Customized bundling has been addressed in literature, however, up until now; the research has been limited to examining products with the same unit costs (Grenci and Watts, 2007; Hitt and Chen, 2005; Wu et al., 2008). Customized bundling is defined as "the right for a consumer to buy a self-customized choice of up to $\mathrm{M}$ goods from among a larger set of $\mathrm{N}$ goods, for a fixed price" (Hitt and Chen, 2005, p. 1482). Although customized bundling has been 
explored, the research has traditionally used low marginal cost goods such as information and digital goods. This has resulted in the assumption of a constant unit cost and the same unit cost for each item (Meyer, 2009). The benefits of giving customers the option to self-select goods in a bundle rather than having the goods preselected by the firm has been shown to improve customer outcomes (Hitt and Chen, 2005). Another form of customized bundling is pure bundling-when a firm sells only the bundle and not (all) the products separately, such as Dell computers which allows customers to self-design their personal computer but does not sell individual parts of the computer (Stremersch and Tellis, 2002). Similar to the custom bundling literature, the personal pricing literature has habitually relied on low marginal cost goods. In addition, the personal pricing literature has used information examining dynamic pricing of one product and not a bundle of products (Choudhary et al., 2005; Yunchuan and Zhang 2006). A gap in research as well as in practice is the dynamic pricing of bundles created through consumer self-selection that consists of a mixture of products at distinct marginal costs. Until now, little discourse has occurred on the pricing of bundles with products of different costs or the pricing of bundles by combining both personalization and customization practices.

The integration of product categories (hardline, softline, and accessory) in the action sport industry will provide consumers added value and convenience. In addition, research has shown that product bundles raise consumers' reservation prices for the product bundle compared with the sum of the conditional reservation prices of the separate products (Stremersch and Tellis, 2002). Product bundling is a strategic tool used to create added value for the customer whereas price bundling is more of a promotional tool that is typically offered for a short time interval. Personalized-customized hybrid bundling is a combination of product and price bundling to target Generation Y by creating an individualistic shopping experience. 


\subsection{Differential Pricing and the Role of Rate Fences}

As bricks-and-clicks retailers increase their capability to gather and process detailed customer information, they acquire the ability to charge different prices to different customers (Liu and Zhang, 2006). Although price discrimination has been established as a successful management tool in generating increased revenue (airlines, hotels, entertainment, and sport) it has not been accepted by all consumers (Cox, 2001; DiMicco et al., 2001; Parris et al., 2012; Smith et al., 1992). Examples of consumer resistance include: Amazon selling the same movies at different prices to different customers; Coca-Cola's utilizing smart vending machines to charge higher prices the hotter the temperature; and Victoria's Secret offering higher discounts to men (Cox, 2001; Haws and Bearden, 2006; Lewis, 2010). Consumers perceive price fairness or price unfairness by interpreting the meaning and significance of both the price offered in conjunction with the rational of why the firm is offering a certain price (Xia et al., 2004). Consequently, in order to successfully adopt a personalized-customized hybrid bundling strategy it is vital for action sport companies to apply differential pricing with the intention of creating a win-win situation for both themselves (the seller) and the consumer.

According to Wirtz and Kimes (2007), in order for differential pricing to be effective firms need to build well-designed rate fences between customers segments. These fences prevent customers who are willing to pay more for items from taking advantage of a lower price that is targeted at a more price-sensitive market segment. In Figure 3 the author proposes three main types of rate fences in the action sport industry: buyer characteristic fences, product-related fences, and service-related fences. 
Table 2 Rate fences in Action Sports

\begin{tabular}{|l|l|l|}
\hline Buyer characteristics & Product-related fences & Service-related fences \\
\hline Sport Subculture Style & Brand Name & Service \\
Gender & Sport & Preferences \\
Sport & Hardline goods & Ability \\
Favorite Professional Rider & Softline goods & Custom fitting \\
Level of Experience & Product designed for: & Instruction \\
Loyalty Membership & Level of Experince & Maintenance \\
& Sport Subcultures Style & \\
\hline
\end{tabular}

It is imperative action sport companies adopting personalized-customized hybrid bundling design rate fences that accurately reflect consumer segments, since this will result in different personalized prices for each customer.

\section{Conceptual framework for personalized-customized hybrid bundles}

\section{1 Personalized-Customized Hybrid Bundles}

The proposed conceptual model for action sports to capture Generation Y (Figure 1)

demonstrates the appeal to the 'cool' consumption of a bundle of goods. The challenge for action sport retailers is how to reach, obtain, and gain the loyalty of Generation Y consumers. Given that action sports as well as 'cool' consumption require multiple products the author proposes the action sport industry adopt a personalized-customized hybrid bundling strategy. The author demonstrates how a MCM system in combination with customer self-selection can be used to create personalized-customized hybrid bundles in the model shown in Figure 2.

The framework presents a model to guide a bricks-and-clicks firm on how to leverage a MCM system to build a personalized-customized hybrid bundling experience. First, the basis of personalizing a product offering begins with buyer characteristics. Then, ensuring the appropriate rate fences are in place; optimizing maximum revenue from each customer while achieving highest levels of customer satisfaction. Third, the MCM system offers personalized 
bundles comprising a mixture of products. Next, the customer is able to manipulate and change the MCM offered personalized bundle to represent the brands and products he or she uses for self-branding. Finally, the MCM system should update the bundle and price based upon selected products and rate fences.

Figure 1 Proposed conceptual model for action sports to capture Generation Y

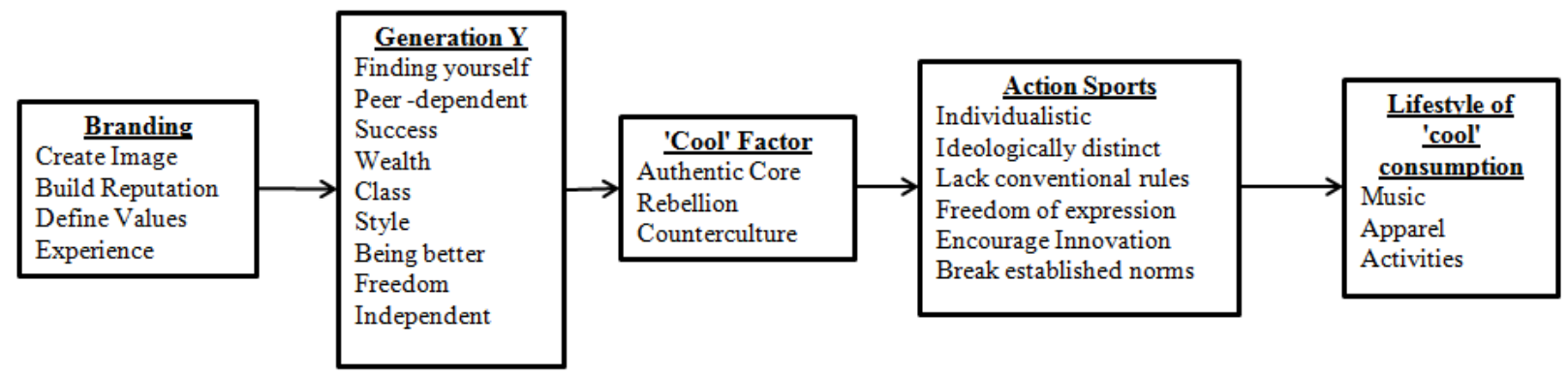

Figure 2 Proposed framework for personalized-customized hybrid bundles

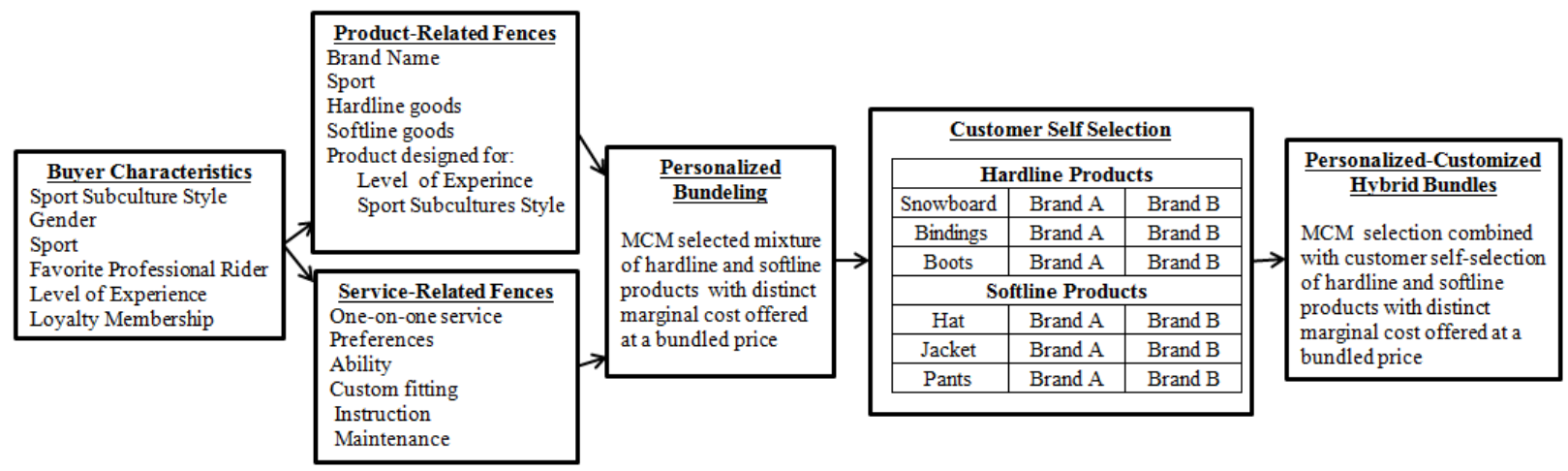

Despite MCM systems enabling bricks-and-clicks retailers the ability to provide increased personalization and customization to benefit their customers (Adamson, 2008; Neslin and Shankar, 2009; Pan et al, 2002; Zhang et al., 2010) this conceptual paper is one of the first to explore combining the elements of personalization and customization. Personalization begins 
with the one-on-one interactive communication between the customer and the MCM system. As customers shop online they enter in their personal preferences while at the same time demonstrating through their interactions what offers or products they consider to be significant (Adamson, 2008; Neslin and Shankar 2009). Currently, personalization is limited to offering consumers product recommendations (Arora et al., 2008). The capability to gather and process buyer characteristics by utilizing a MCM system facilitates the ability for a retailer to charge different prices to different customers (Liu and Zhang, 2006). Offering individual hybrid product bundles is the next step in personalization. Individual pricing utilizing differential pricing has been examined using one product and not product bundles (Choudhary et al., 2005; Yunchuan and Zhang 2006). Differential pricing is effective when firms build rate fences between customers segments (Wirtz and Kimes, 2007). In the action sport industry the author proposes the MCM system place customers in different segments based on buyer characteristics, productrelated fences, and service-related fences (Figure 3). After analyzing the buyer characteristics as well as shopping patterns the MCM system places the customer into the appropriate rate fence, which will determine the differential price offered to the customer for his or her own personalized hybrid bundle.

Although bundling has attracted the attention of academics and industry, there is very limited research on examining the pricing of hybrid bundles consisting of a mixture of products with different marginal and unit costs (Meyer, 2009). To date, the research has been limited to examining low margin cost products such as information or digital goods that have the same unit costs (Grenci and Watts, 2007; Hitt and Chen, 2005; Meyer, 2009; Wu et al., 2008). The concept of personalized hybrid bundles generated by a MCM system has not yet been explored in the literature or practice. The next step in the proposed conceptual framework (Figure 4) is allowing 
customers to customize their personalized hybrid bundles, which makes them stakeholders in the buying process. By providing customers a proactive role in the exchange process makes the shopping experience a form of entertainment, provides consumers a higher locus of control, and increases consumer lock-in (Wolfinbarger and Gilly, 2001; Zauberman, 2003). Although customized bundling improves customers outcomes (Hitt and Chen, 2005), the pricing of customized bundles with products consisting of different marginal and unit cost has not been investigated. The author's proposed conceptual framework combines personalization and customization to build a hybrid bundle that consists of products with different marginal and unit costs, offered to a customer at an individualized price, that are predetermined by rate fences. The proposed conceptual model for action sports to capture Generation Y (Figure 2) combined with the proposed personalized-customized hybrid bundling model address the use of bundling and 'cool' consumption to reach Generation Y action sport consumers.

\section{Implications and future research}

The advancement of technology, information processing, and MCM systems has made personalized-customized hybrid bundling a tangible model for bricks-and-clicks retailers to gain a competitive advantage. Combining personalization and customization, two forms of one-onone marketing, facilitates the modification of the firm's offering to target an individual consumer (Arora et al., 2008; Peppers and Rogers, 1999; Shaffer and Zhang, 2002). This is an extreme form of segmentation that creates a virtual dialogue where the customer acts and she or he expects the retailer to (re)act in a certain way (Adamson, 2008). From a theoretical standpoint, the author defines personalized-customized hybrid bundling and proposes using these bundles to target Generation Y action sports consumers. A conceptual model is developed explaining how action sports capture Generation Y, which links divergent streams of literature on branding, 
coolness, lifestyle marketing, Generation Y, and action sports. The conceptual framework of personalized-customized hybrid bundling extends the personalization, customization, bundling, and pricing literature.

To date, there has been a limited research combining personalization and customization. Although, bundling has been explored extensively, hybrid bundles and customized bundles are relatively new concepts (Grenci and Watts, 2007; Hitt and Chen, 2005; Meyer, 2009; Wu et al., 2008). In addition, the pricing strategies for these bundles have assumed the same unit cost for each item and has only used low marginal cost goods (Hitt and Chen, 2005; Meyer, 2009). Differential pricing has been explored selling separate items; it has not been explored in the bundling literature (Choudhary et al., 2005; Yunchuan and Zhang 2006). This conceptual paper generates a new theoretical base for hybrid bundling, in particular for the action sport industry, which can be extended to the greater retail industry.

In terms of practical implications, the proposed models and conceptual framework enable retailers to have a personal virtual dialogue with consumers while allowing the customers to customize their unique bundle of goods. Providing freedom and control in the purchasing process specifically targets the buyer characteristics of Generation Y. Personalized-customized hybrid bundling addresses the disloyalty of Generation Y by increasing consumer lock-in through personalized self-selection in addition to providing a lower price point through bundling. Combing product and price bundling is designed to limit the consumer's ability to comparison shop individual items in the bundle while increasing the entertainment value of the shopping experience. Personalized-customized hybrid bundling is a strategic tool designed to create a winwin situation for the customer and the retailer. The integration of products in a bundle provides consumers added value and convenience. Product bundles raise consumers' reservation prices for 
the product bundle compared with the sum of the conditional reservation prices for the separate products (Stremersch and Tellis, 2002). Through the use of personalized-customized hybrid bundling the retailer increases revenue and gains brand loyalty.

This paper opens the opportunity to be continued in multiple research streams: branding, action sports, Generation Y, coolness, lifestyle marketing, personalization, customization, bundling, self-selection, multi-channel customer management, personalized-customized hybrid bundling, and pricing. The author predicts the following:

- Generation Y action sports consumers will buy more products when offered in a personalized-customized hybrid bundle

- Action sport consumers with less familiarity with the sport (e.g., beginners to intermediate participants) will prefer bundles over individually sold items, whereas, consumers with high familiarity with the sport (e.g., advanced to professional) will prefer individual items compared to bundles.

- Action sport consumers will have a different willingness to pay and reservation range based on the sport, frequency participation, and ability. The higher all of these combined factors will result in a higher reservation range for the individual consumer.

- Personalized-customized hybrid bundling using multi-channel customer management will result in increased consumer loyalty and purchases, and therefore improve a firm's ability to make higher profits

The author's propositions, models, and conceptual framework offer several intriguing directions for future research.

This paper is the first attempt at defining a conceptual model for how action sports captures Generation Y, in addition to proposing a framework for personalized-customized hybrid bundles. Further investigation should test and refine the models and conceptual framework presented here. The potential impact of personalized-customized hybrid bundling could benefit the action sports industry by resulting in increased revenue, more engaged and brand loyal customers, and facilitate a transition towards a marketing oriented market approach. In order to 
increase brand loyalty action sports companies need to engage the consumer by enabling them to build personalized-customized hybrid bundles. The retail experience offered through allowing customers to construct their own unique bundles provides the control, freedom, fun, and personal one-on-one interaction Generation Y expects. Personalized-customized hybrid bundling is a viable way for bricks-and-clicks retailers to gain a competitive advantage, capture Generation Y, create loyal customers, and achieve greater revenue. 


\section{References}

Adamson, A. P. (2008). Brand Digital: Simple ways top brands succeed in the digital world. New York; NY: Palgrave Macmillan.

Archer, A. (2012). Direct Marketing to Generation Y. Hanover Research [online]. Retrieved March 18, 2013 from http://www.hanover research.com/2012/09/direct-marketing-togeneration-y/

Amato, C., Peters, C., and Shao, A. (2005). An exploratory investigation into NASCAR fan culture. Sports Marketing Quarterly, 14, 71-83.

Aquino, J. (2012). Gen Y; The Next Generation of Spenders. CRM magazine [online]. Retrieved March 18, 2013 from http://www.destinationcrm.com/Articles/Editorial/MagazineFeatures/Gen-Y-The-Next-Generation-of-Spenders-79884.aspx

Arora, N., Dreze, X., Ghose, A., Hess, J., Iyengar, R., Jing, B., Joshi, Y., Kumar., V., Lurie, N., Neslin, S., Sajeesh, S., Su, M., Syam, N., Thomas, J., and Zhang, Z. J. (2008). Putting one to one marketing to work: Personalization, customization, and choice. Springer Science + Business Media, 19, 305-321, doi: 10.1007/s11002-008-9056-z

Bakewell, C., and Mitchell, V.W. (2003). Generation Y female consumer decision-making styles. International Journal of Retail and Distribution Management, 31(1), 95-106.

Beal, B. and Wilson, C. (2004), “'Chicks dig scars': commercialization and the transformations of skateboarders' identities", in Wheaton, B. (Ed.), Understanding Lifestyle Sport: Consumption, Identity and Difference, Routledge, Abingdon, pp. 31-54..

Business Week (1999). Cover story: Generation Y (February 15) http://www.businessweek.com/1999/99_07/b3616001.htm 
Choudhary, V., Ghose, A., Mukhopadhyay, T. and Rajan, U. (2005) Personalized pricing and quality differentiation. Management Science, 51(7), 1120-1130.

Cox, J.L. (2001). Can differential prices be fair? The Journal of Product and Brand Management, 10 (4/5), 264-275.

Dar-Nimrod, I., Hansen, I.G., Proulx, T., Lehman, D.R., Chapman, B.P., and Duberstein, P.R. (2012). Coolness: An Empirical Investigation. Journal of Individual Differences, 33(3), $175-185$.

Desbordes, M. (2002). Empirical analysis of the innovation phenomena in the sports equipment industry. Technology Analysis and Strategic Management, 14(4), 481-491.

DiMicco, J.M., and Greenwald, A., and Maes, P. (2001). Dynamic pricing strategies under a finite time horizon. Retried April 7, 2010 from http://doi.acm.org/10.1145/501158.501169

Escalera, K. (2012). Generation Y: Luxury’s Most Buoyant Market. Luxury Society [online]. Retrieved March 20, 2013 from http://luxurysociety.com/articles/2012/05/generation-yluxurys-most-buoyant-market

Ferguson, S. (2011). A global culture of cool? Generation Y and their perception of coolness. Young Consumers: Insight and Ideas for Responsible Marketers, 12(.3) 265-275.

Fernandez, P.H. (2009). Impact of branding on Gen Y's choice of clothing. Journal of the South East Asia Research Centre for Communications and Humanities, 1(1), 79-95.

Funk, D.M. (2003). Sport consumer behavior: Direction assessment and direction. Sport Marketing Quarterly, 12, 200-204. 
Giannoulakis, C., and Apostolopoulou, A. (2011). Implementation of a multi-brand strategy in action sports. The Journal of Product and Brand Management, 20(3), 171-181. doi: http://dx.doi.org/10.1108/10610421111134905

Gladden, J. (2006). Interview with Peter Carlise, Director of Olympics and Actions Sports for Octagon. Sport Marketing Quarterly, 13, 133-137.

Goodman, B., and Dretizin, R. (2001). The Merchants of Cool. Frontline PBS [online]. Retrieved March 23, 2013 from http://www.pbs.org/wgbh/pages/frontline/shows/cool/

Grenci, R., and Watts, C. (2007). Maximizing customer value via mass customized e-commerce services. Business Horizons, 50, 123-135.

Hargrove, K (2012). X Games 2012 ratings soar. Transworld Business [online]. Retrieved March 18, 2013 from http://business.transworld.net/86566/news/x-games-2012-ratings-soar/ Hyllegard, K., Yan, R., Ogle, J., and Attmann, J. (2011). The influence of gender, social cause, charitable support, and message appeal on Gen Y's responses to cause-related marketing. Journal of Marketing Management, 27(1), 100-123).

Hanan, M. (1980). Life-style marketing. How to position products for premium profits. New York, NY: Amacom.

Haws, K.L., and Bearden, W. O. (2006). Dynamic pricing and consumer fairness perceptions. Journal of Consumer Research, 33, 304-311.

Herbig, P., Koehler, W., and Day, K. (1993). Marketing to the baby bust generation. Journal of Consumer Marketing, 10 (1), 4-9.

Hitt, L., and Chen, P. (2005). Bundling with customer self-selection: a simple approach to bundling low marginal cost goods. Management Science, 51(10), 1481-1493. 
Huffman, C., and Kahn, B.E. (1998). Variety for sale: Mass customization or mass confusion? Journal of Retailing, 74 (4) 491-513.

Kaplan, A., and Haenlein, M. (2010). Users of the world, unite! The challenges and opportunities of Social Media. Business Horizons, 53, 59-68.

Keller, K.J. (1993). Conceptualizing, measuring and managing customer-based brand equity. Journal of Marketing, 57(1), 1-22.

Koranteng, J. (2002). Extreme ambitions, AdAgeGlobal, 1(7), 14.

Lazarevic, V. (2012). Encouraging brand loyalty in fickle Generation Y consumers. Young Consumers: Insight and Ideas for Responsible Marketers, 13(1), 45-61.

Lewis, M. (2010, March). Rewarding some and punishing others. Paper session presented at the meeting of 2010 Mays Marketing Research Camp, Texas AandM University, TX.

Liechty, J., Ramaswamy, V., and Cohen S. H., (2001). Choice menus for mass customization: An experimental approach for analyzing customer demand with an application to a web based information service. Journal of Marketing Research, 38(2), 183-196.

Lilien, G.L., Kotler, P., and Moorthy (1992), Marketing Models, Prentice Hall, Englewood Cliffs, NJ (LKM).

Liu, Y., and Zhang, Z. J. (2006). The benefits of personalized pricing in a channel. Marketing Science, 25(1), 97-105.

Meyer, J. (2009). Essays on hybrid bundle pricing. Doctorial Dissertation, Department of Business Administration at Mays, University of Texas AandM.

Morgan, R.M., and Hunt, S.D. (1994). The commitment-trust theory of relationship marketing. Journal of Marketing, 58(3), 20-38. 
Neslin, S., and Shankar, V. (2009). Key issues in multichannel customer management: Current knowledge and future directions. Journal of Interactive Marketing, 70-81.

Noble, S., Haytko, D., and Phillips, J. (2009). What drives college-age Generation Y consumers? Journal of Business Research, 62, 617-628.

Novak, L., Thach, L., and Olsen, J.E. (2006). Wowing the millennials: Creating brand equity in the wine industry. Journal of Product and Brand Management, 15(5), 316-23.

Nusir, K., Parsa, H.G., and Cobanoglu, C. (2011). Building a model of commitment for Generation Y: An empirical study on e-travel retailers. Tourism Management, 32(4), 833-843.

Pan, X., Venkatesh, S., and Ratchford, B. (2002). Price competition between pure play versus bricks-and-clicks e-tailors: Analytical model and empirical analysis. Economics ofthe Internet and E-Commerce, 11, 29-61.

Parris, D., Drayer, J., and Shapiro, S. (2012). Developing a pricing strategy for the Los Angeles Dodgers. Sports Marketing Quarterly, 21, 256-264.

Peppers, D., and Rogers, M. (1997). The one to one future. New York. Doubleday.

Rajamma, R. K., Pelton, L.E., Hsu, M.K., and Knight, D. K. (2010). The impact of consumers' need for uniqueness and nationality on Generation Y's retail patronage behaviors: Investigating American and Taiwanese consumers. Journal of Global Marketing, 23(5), $387-410$.

Rinehart, R. E. (2000). Arriving sport: Alternatives to formal sports, in Jay Coakley and Eric Dunning (eds.), Handbook of Sports Studies. Thousand Oaks, CA: SAGE Publication. 
Saxton, G. (2007). Collections of cool. Young Consumers: Insights and Ideas for Responsible Marketers, 6(2), 18-27.

Schewe, C.D., and Noble, S.M. (2000). Market segmentation by cohorts: The value and validity of cohorts in American and abroad. Journal of Marketing Management, 16, 129-42.

Shaffer, G., and Zhang, Z. J. (2002). Competitive one-to-one promotions. Management Science, 48(9), 1143-1160.

Shah, K. (2004). From innovation to firm formation in the windsurfing, skatingboarding, and snowboarding industries," University of Illinois Working Paper, 05-0107.

Smith, B.C, Leimkuhler, J.F, and Darrow, R.M. (1992). Yield management at American Airlines. Interfaces, 22 (January-February), 8-31.

Stone, M., Stanton, H., Kirkham, J., Pyne, W. (2001). The digerati: Generation Y finds its voice. Why cannot brands do the same? Journal of Targeting, Measurement and Analysis for Marketing, 10(2), 158-167.

Stremersch, S., and Tellis, G. (2002). Strategic bundling of products and prices: A new synthesis for marketing. Journal of Marketing. 66, 55-72.

Syrett, M., and Lammiman, J. (2004). Advertising and millennials. Young Consumers: Insights and Ideas for Responsible Marketers, 5(4), 62-73.

Today (2010). NBC strikes ratings gold-Olympics beat 'Idol'. Today.com [online]. Retrieved March 18, 2013 from http://www.today.com/id/35460404\#.UUdxGByG18H

Turner, G. (1999). Teens the most global market of all. Fortune International, 16 May.

Wheaton, B. (2004), "Mapping the lifestyle sport-scape”, in Wheaton, B. (Ed.), Understanding Lifestyle Sport: Consumption, Identity and Difference, Routledge, Abingdon, pp. 1-28. 
Williams, C. (personal communication, December 1, 2012) Personal interview at Performance Ski and Surf in Orlando, FL.

Willigan, G. (1992). High-performance marketing: An interview Nike's Phil Knight, Harvard Business Review, 70 (4), 90-101

Wingfield, N. (2011). Camcorder popular with surfers looks to ride professional market. Wall Street Journal [online]. Retrieved March 23, 2013 from http://online.wsj.com/article/SB10001424052748704587004576245103843012200.html

Wirtz, J., and Kimes, S.E. (2007). The moderating role of familiarity in fairness perceptions of revenue management pricing. Journal of Service Research, 9(3), 229-240.

Wolfinbarger, M., and Gilly, M. (2001). Shopping online for freedom, control, and fun. California Management Review, 43(2), 33-55.

Won, K. (2002). Personalization: Definition, Status, and Challenges ahead. Journal of Object Technology, 1(May-June), Retrieved from http://www.jot.fm/issues/issue_2002_05/column3, 29-40.

Wu, S., Hitt, L., Chen, P., and Anandalingam, G. (2008). Customized bundle pricing for information goods: A nonlinear mixed-integer programming approach. Management Science, 44(3), 608-622.

Xia, L., Monroe, K.B, and Cox, J.L. (2004). The price is unfair! A conceptual framework of price fairness perceptions. Journal of Marketing, 68, 1-15.

Yunchuan, L., and Zhang, Z. (2006). The benefits of personalized pricing in a channel. Marketing Science, 25(1), 97-105.

Zauberman , G. (2003). Intertemporal dynamics of consumer lock-in. Journal of Research, 30(Dec), 405-419. 
Zhang, J., Farris, P.W., Irvin, J.W., Kushwaha, T., Stennburgh, T.J., and Weitz, B.A. (2010). Crafting multichannel retailing strategies. Journal of Interactive Marketing, 24(2), 168180.

Zettelmeyer, F. (2000). Expanding to the Internet: Pricing and communications strategies when firms compete in multiple channels. Journal of Marketing Research, 293-308. 